\title{
Testing a Model of the Threat of Street Sexual Harassment in Egypt: Implications for Social Work Education
}

\author{
Hussein Soliman (Corresponding author) \\ School of Human Science, Southern Illinois University Carbondale \\ 475 Clocktower Drive, Carbondale, IL 62901, USA \\ Tel: 1-618-453-2243 E-mail: soliman@siu.edu
}

Jennifer Koran

School of Education, Southern Illinois University Carbondale

625 Wham Drive, Carbondale, IL 62901, USA

Tel: 1-618-453-2311 E-mail: jkoran@siu.edu

Amal Abdelmordi Abdelmonem

Department of Social Sciences, Qatar University

Received: January 9, 2021 Accepted: February 9, 2021 Published: February 11, 2021

doi:10.5296/ijsw.v8i1.18167 URL: https://doi.org/10.5296/ijsw.v8i1.18167

\begin{abstract}
This study tested a model of Egyptian women's well-being and perception of the threat of sexual harassment. The model was drawn from multiple theoretical frameworks, including the vulnerability perspective, objectification theory, and religious perspectives. Nine variables in the model reflect societal, interpersonal, and cultural variables that are believed to relate to women's views about threats and social risks related to sexual harassment. A total of 1,977 Egyptian women aged 19-45 years voluntarily participated in the study. Path analysis showed that exposure to street sexual harassment was the strongest predictor of both perception of the threat of sexual harassment and a sense of vulnerability to sexual harassment. However, more nuanced results from the model had implications for social work education and research. This
\end{abstract}


study fills an important gap in social work education related to sexual harassment by examining a complex web of interpersonal, environmental, and cultural factors relevant to women's view of the threat of sexual harassment.

Keywords: Sexual Harassment, Egyptian culture, social work education, vulnerability

\section{Introduction}

Sexual harassment can be characterized by women's exposure in public to various forms of verbal and physical assaults (Laniya, 2005; McCurm, 2017), posing a serious threat to women's freedom (Dhilon, \& Bakaya, 2014) and a challenge to women's confidence (Fairchild \& Rudman, 2008). A critical characteristic is that the phenomenon of sexual harassment is complex, affected by many societal, interpersonal, and cultural factors. Education plays a key role in addressing such complex social phenomena.

However, the current social work curriculum in many countries across the world neither thoroughly nor specifically integrates knowledge on sexual harassment into social work practice and research. For example, the content on the topic of sexual harassment in courses included in social work schools and institutes suffers from being fragmented, narrow, and inconsistent (Lurio, 2020; Soliman, Abdelmonium, \& Koran, 2020; Stanley, 2000). The few studies on sexual harassment from the social work perspective have focused on identifying types of sexual abuse (Crittenden, 2009), its causes (Al-Bakar, Al-Adailah, \& Al-Nablisi, 2017; Willness, Steel, \& Lee, 2017), its impacts on victims, and the programs that are developed and implemented to provide protection and safety for female victims (Avina, \& O’Donohue, 2002; Gutek, \& Koss, 1993). Furthermore, limited studies focused on societal recognitions, awareness, laws, and regulations developed to address sexual harassment (Baxi, 2001; Cowan \& Ullman, 2006) and the cultural ramification of such a devastating phenomenon (Wasti, Bergman, Glomb, \& Drasgow, 2000).

The consequence is graduates of social work programs may have limited understanding of factors related to sexual harassment and how women perceive its' threat. There is a need for social workers to understand how sexual harassment is a product of social, economic and cultural dynamics within society (Laurio, 2020). Summarizing the emphasis of social work on sexual harassment, Clancy et al. (2014) emphasized the importance of "Raising awareness of students and practitioners of the presence of hostile work/street behaviors, discrimination, harassment, and assault (particularly for women), creating guidelines for respectful behavior, and adopting independent reporting and enforcement mechanisms" (p. 8). Graduates of social work programs who lack such knowledge may be less prepared to work with models of intervention with victims of sexual harassment.

In the past 20 years the phenomenon of sexual harassment has been on the rise in the Arab world and specifically in Egypt (Al-Kylani, 2014; Bo-Shaljeem, 2017; Ilahi, 2009; Soliman, Abdelmonem, \& Koran, 2020). Associated changes in behavior, attitude, and sense of responsibility in Egypt have been particularly notable since the political and cultural shifts of 2011 (El-Ashmawy, 2017). Thus, Egypt is currently a particularly appropriate environment for both research and the development of interventions related to sexual harassment. This 
study focuses on modeling factors related to Egyptian women's perception of the risk and threat of street sexual harassment by testing a path model that incorporates relevant interpersonal, cultural, and societal factors.

\section{Literature Review}

In an attempt to conceptualize sexual harassment, Wasti et al. (2000) presented a behavioral construct composed of three related but conceptually distinct and non-overlapping dimensions: gender harassment, unwanted sexual attention, and sexual coercion. Gender harassment comprises offensive, misogynist, or degrading remarks and behavior not necessarily intended to elicit sexual cooperation. Unwanted sexual attention can take the form of street harassment. The effects of street harassment on women vary, including anger, fear, depression, anxiety, irritability, humiliation, embarrassment, shame, alienation, helplessness, and vulnerability (Gloppen, Gower, Mc Morris, \& Eisenberg, 2017). Experiencing sexual harassment makes victims feel afraid, nervous, and hesitant about things that were once no problem. It changes victims' lives and cheats them out of happiness, fun, and peace of mind, which ultimately influences the victims' overall psychological condition, including alienation, loss of self-confidence, apathy, helplessness, hopelessness, and a perception of diminished control over their bodies (Lichty \& Campbell, 2012; Strauss, 2012).

\subsection{The Egyptian Experience with Street Harassment}

In the last 50 years, Egyptian women, despite various societal challenges, have made progress in many areas, especially education and other areas of public service, such as employment, community development, sports, and arts (Carco \& Fayolle, 2017). However, the dominant and traditional views of women are reflected in certain attitudes, values, and behaviors (Hassan, 2008). For example, in Egypt women represent only $23.1 \%$ of the country's workforce (The World Bank Group, 2018). This puts women in Egypt at a disadvantage in terms of their contribution and ability to participate in the process of developing and formulating social policies (Radwan \& Refriz, 2006).

Researchers indicate that violence and insult have become part of the social fabric and the new reality of Egyptian society (Egyptian Center for Women's Rights, 2007; Gad-Allah, 2016). A common form of sexual harassment that is a widespread phenomenon in Egypt is street harassment (Laniya, 2005). Life in the streets of Cairo, Egypt, is a major point of convergence. The streets are a convergence of varied forms of social life and human activities, a setting where women and young girls experience hostilities and sexual harassment on a daily basis (Egyptian Center for Women's Rights, 2007).

Looking at the social and economic conditions in Egypt, there has been a drastic increase in the population, and unemployment for citizens aged 15-24 years old has been on the rise (El-Ashmawy, 2017). When not in school, those unemployed youths spend their time idling the streets looking for any type of behavioral experimentation (Amin, 2006). Advocates for human and women's rights believe that the spread of sexual harassment in Egypt may relate to the lack of implementation of strict laws against violators, which reduces women and girls' ability to be safe and move freely without being exposed to sexual threats and intimidations 
(Phadke, 2013).

\subsection{Societal and Cultural Factors Related to Women's Views of Sexual Harassment}

Researchers have agreed that specific norms and beliefs within the Arab culture, that is, the male domination perspective, may promote a sense of power among young males and influence their attitudes about women (Al-Ajami, 2016). However, the culture among young males may also be shaped by weak or inconsistent parenting patterns, including a lack of sexual education, strict parenting, or spoiling children (Gad- Allah, 2016). The absence of religious reasoning and the rising of cost of marriage are also thought to be among the causes of sexual harassment (Okeal, 2015). Ghanem (2015) identifies three factors that tend to promote sexual harassment behavior in Egypt: (a) the rise of unemployment among youth, (b) the deterioration of the education system, and (c) the spread of moral corruption. Conely and Ramsey (2011) believe that the visual media often convey the notion that women can be reduced to their sexualized bodies and body parts. Similarly, one study reported that women are portrayed as sex objects in 50\% of magazine advertisements (Linder, 2004). Clearly, there are many elements of culture that can contribute to perceptions of sexual harassment.

Religious belief is also likely an element important to Egyptian culture that influences women's perception of the threat of sexual harassment. Drawing on existing theory of religiosity, nine dimensions of religiousness and spirituality have been defined, including public religious activities, private religious activities, positive religious coping, negative religious coping, religious intensity, forgiveness, daily spiritual experience, beliefs and values, and giving-to-income ratio (Abu-Raiya, 2008). Koenig \& Larson (2001) indicate that such religious beliefs and practices are related to greater life satisfaction, happiness, positive affect, and higher morale. Similar levels of positive association were found between religiousness and hope, optimism, purpose, and meaning. Al-Issa (2000) emphasizes that the salutary effects of religion have also been demonstrated with other dimensions of mental health and illness, such as self-esteem and mastery (Krause \& Tran, 1989), depressive symptoms (Koenig, Kavel, \& Ferrel, 1988), anxiety (Atkinson \& Malony, 1984), and emotional adjustment (Blazer \& Palmore, 1976).

\subsection{Social Work Education and Sexual Harassment}

Given the many societal and cultural factors related to women's views of sexual harassment, social workers have an important role to play in addressing this problem. However, research on integrating sexual harassment into social work education has been limited and sporadic. Earlier studies in social work on sexual harassment were limited in scope. They focused on peer sexual harassment (Fineran, \& Bennet, 1998, O'Keefe, Brockopp, \& Chew, 1986) and a review of sexual assault experiences reported in college web-sites (Schwartz, McMahon, \& Broadnax, 2015). Recently studies in social work have shifted toward identifying risk and characteristics of harassment in social work practicum (Moylan, \& Wood, 2016), examining the process of trauma caused by sexual harassment experiences (Bent-Goodley, 2018) and the development of a measure to assess teen girls' perception of the threat of sexual harassment (Soliman, et al., 2020). 
The content on sexual harassment was not clearly integrated in the social work curriculum. For example, social work educators have yet to decide whether to include topics of social harassment within human behavior courses as part of environmental threat that may influence females' social, emotional and physical development, or address it in social work practice courses as part of assessment and intervention models to address the impact of sexual harassment on victims and their adjustment. Still, research in social work has not reached the point where sexual harassment can be defined and measured from various conceptual and theoretical levels. Likewise, addressing sexual harassment on social policy or macro levels has been insufficient (Laurio, 2020).

\section{Theoretical Framework}

This study relies on the vulnerability and objectification perspectives as the foundation for examining the dynamics of street sexual harassment. The vulnerability perspective explains the conditions that tend to expose women and girls to the threat of harassment (Gilson, 2016; Nardulli, Kalev, Leetaru, \& Hayes, (2011). Women and girls are susceptible to victimization in various ways, "harmful wrongs, exploitation, or threats to one's interests or autonomy" (Mackenize, Rogers, \& Dodds, 2014, p. 6). The feminists assume that vulnerability represents a state of tension and ambiguities of experiences of gender, sexuality, and power in contemporary life (Alcoff, 2009). Considering the dominant belief in certain societies that women are incapable of contributing to the social and political life, the vulnerability perspective explains how such perceptions undermine women's abilities to achieve changes and enforce their wills. This positions women as a target for exploitation (Sarewitz, Pielke, \& Keykhah, 2003).

The objectification perspective presents another dimension of sexual harassment, as women become the target of harassment due to being seen as figures or sex objects. The implicit associations between women's bodies and other objects or concepts may influence an individual's thoughts and attitudes toward females (Rudman \& Mescher, 2012). Accordingly, sexual objectification of females may lead to viewing their behavior and clothing as a justification for being a target and thus put the blame on the victim (Loughnan, Pina, Vasquez, \& Puvia, 2013).

Sexual objectification theory recognizes the implicit and explicit attitudes and specific cues that support the view of females as targets for sexual harassment (Heflick \& Goldenberg, 2014). Such assumptions promote acknowledgment of women's appearance and moves. In this perspective, men and women perceive females as less competent, less intelligent, less possessing of human qualities and mentality, and lacking in agency (Cikara, Eberhardt, \& Fiske, 2011). In sum, a growing body of sexual objectification research has mainly focused on why and how people perceive women in sexualized ways, but it remains unclear whether exposure to sexually objectified depictions of women influences perceptions of women in real life.

\subsection{The Sexual Harassment Model}

Based on the literature and the theoretical framework, constructs were selected to form a 
model of women's perception of threat of street sexual harassment. As shown in Figure 1, the model presents a complex web of relations among these constructs. The model incorporates the role of society, culture, and social pressure in Egypt and how Egyptian women perceive themselves in relation to their views of the threat of street sexual harassment. Relying on the hypothesized model, the purpose of this study was to explore the meaning of the threat of sexual harassment by focusing on women's interpersonal characteristics, their cultural views, and their experience with harassment.

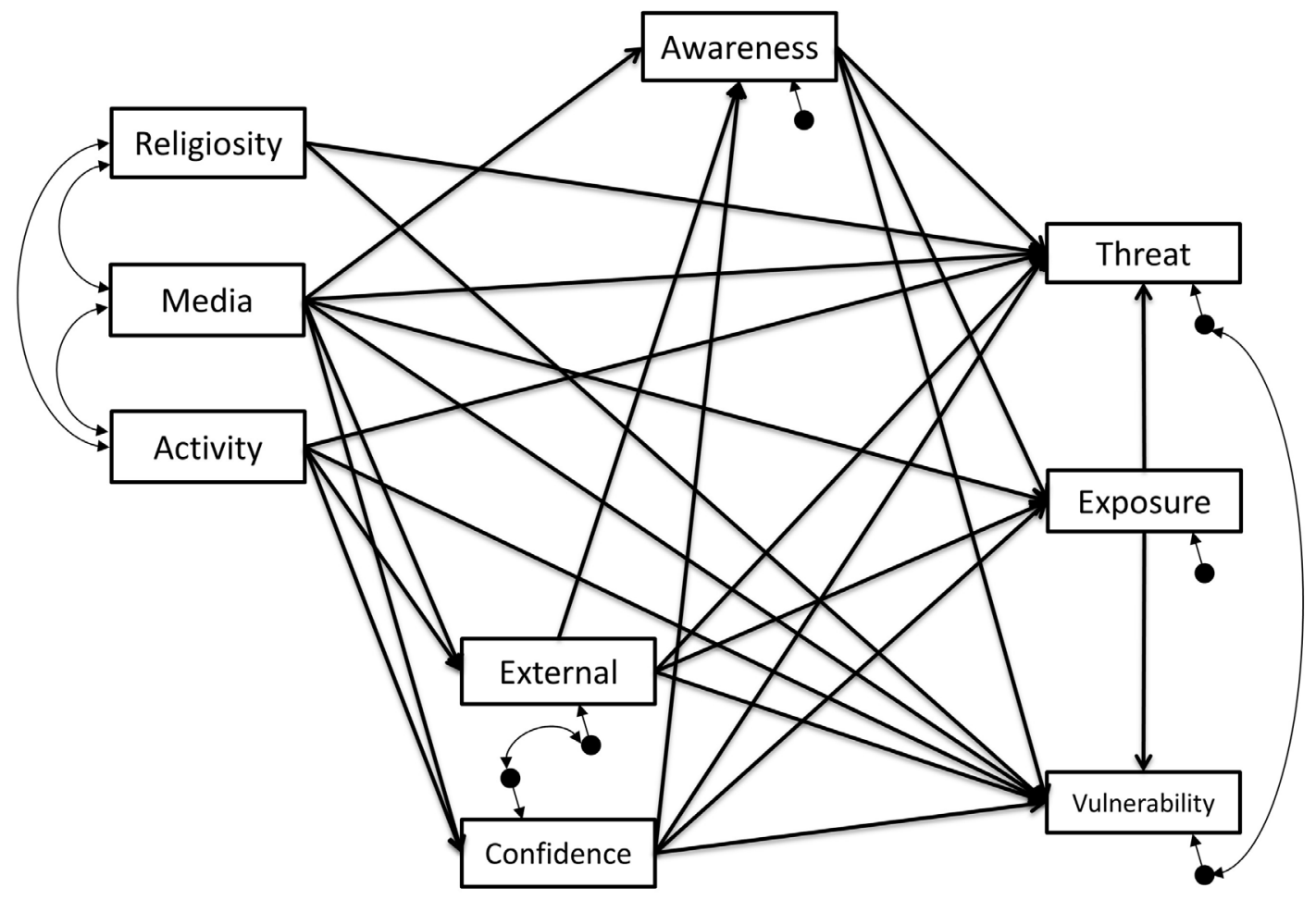

Figure 1. Hypothesized relations among society, culture, and social pressure constructs

This model was developed a priori based on the literature and tested empirically in the study.

\section{Method}

\subsection{Study Design, Population and Sampling}

This study used a survey design to examine Egyptian women's views of the threat of street harassment. The population in the study included women aged 19-45 years from various segments of Egyptian society, including place of living (rural or urban), social status (single, married, separated), and types of social and work activities (housewife, students, private or public employment). The logic behind the selection of women with these characteristics is that they are exposed to the public on a daily or weekly basis. Excluded from this population are teen girls who are less than 19 years old, as they were included in a separate study.

Two cluster selection methods were used in this study. First, the researcher selected 16 governorates out of the 29 Egyptian governorates that are spread geographically from the Mediterranean Sea to the south part of Upper Egypt close to the border of Sudan. Second, a random sample of four governorates out of eight governorates that border Cairo, the capital 
of Egypt was selected to minimize travel and the cost of applying the study in distant governorates. In addition to those four governorates, the Cairo governorate was added to the sample due to its large population and its diverse group of women. Within each selected governorate a convenience sample of females was recruited through colleges and work places (factories, private offices, stores, and service agencies, such as hospitals and social welfare agencies). Finally, housewife females were included in the study sample though door to door recruitment.

\subsection{Instrumentation}

The study survey consisted of 68 items distributed on seven construct domains, as well as demographic questions, such as age, education, marital status, residency, type of employment, and nature of participation in social activities. The seven construct measures are as follows.

\subsubsection{Activity and Social Engagement Scale}

Six items were developed to measure the level of participation in social, sports, and cultural activities. Participation implies the level of confidence, maturity, and trust women gain by taking part in different activities that will enable them to learn about society and culture. These growth activities provide the opportunity to interact with people and share ideas though open meetings, volunteering in community initiatives, and participating in discussions with various groups. The Cronbach's alpha in a prior study with Egyptian women was .83 (Soliman, et al., 2021). In the present study Cronbach's alpha was .83.

\subsubsection{Religiosity Scale}

This domain assesses the extent that religion influences a woman's attitudes and opinion regarding her view of people's behavior, interaction, and conduct. Nine items were developed based on the work of Abu-Raiya (2008) on the assessment of religiosity of people. These items identify the effect of religion on people's behavior, awareness of the influence of religion on people's thoughts, making life decisions based on religious instructions, the concept of rewards and punishment in religion, and how religion influences a person's views and judgment. The Cronbach's alpha in a prior study with Egyptian women was 90 (Soliman et al., 2021). In the present study Cronbach's alpha was .89.

\subsubsection{Society Awareness Scale}

This construct refers to the level of understanding of sexual harassment in social, cultural, and legal aspects of society. The construct is based on the assumption that societal realization of the risk and the effect of sexual harassment on the victims and the moral standards of the community are influenced by the political environment, the economic conditions, and the stability of the living environment. In other words, when a balance between life demands and supplies is lacking, people feel insecure about their own existence, and the rate of crime may rise. Accordingly, 12 items were developed based on the societal stability protocol (Nardulli et al., 2011). Items focused on sense of stability, law-breaking behaviors, inconsistency in punishment, sense of security, protection of citizens, and general level of frustration. The Cronbach's alpha in a prior study with Egyptian women was .92 (Soliman et al., 2021). In the 
present study Cronbach's alpha was .91.

\subsubsection{Media Impact Scale}

Individuals in any society are open to experience many types of media influences regarding the nature of sexual and intimate relationships, which may imply the normalization of certain aggressive sexual behaviors (Baker, 2005; Conely \& Ramsey, 2011 Specifically, the items measure females' perception of violent messages portrayed in the media, the stimulation of sex and hidden meaning behind the media content, the presentation of crime without discussion or punishment, the media views of women's abilities, and the ethical standards of harassment as a crime in society. The Cronbach's alpha in a prior study with Egyptian women was .91 (Soliman et al., 2021). In the present study Cronbach's alpha was 92.

\subsubsection{Exposure to Sexual Harassment Scale}

This domain is measured using 10 items that identify the level of harassment behavior a woman experiences during her daily life. The items were adapted from the Sexual Experiences Questionnaire (Fitzgerald, Magley, Drasgow, \& Waldo, 1999), the Wilson (2010) survey, and the work of Wasti et al. (2000). The items include types of verbal and nonverbal remarks a woman may hear or suggestive stories or sexual discussion revealed with others in the woman's presence. The Cronbach's alpha in a prior study with Egyptian women was 95 (Soliman et al., 2021). In the present study Cronbach's alpha was .95.

\subsubsection{Threat and Vulnerability Scale}

This construct domain refers to women feeling fear, worry, and concern of being targeted as a victimization of harassment. Ten items were developed from existing literature to reflect how a woman feels a sense of vulnerability to harassment, lack of safety measures for protection, and lack of laws and implementation of rules in the society to deter violators or protect women's rights. Items in this domain were adopted from Estrada et al. (2011), Fitzgerald et al. (1999), and Jensen and Gutek's (1982) instruments on women's perception of harassment. A prior study with Egyptian women found this scale had two factors: threat, Cronbach's alpha .88, and vulnerability, Cronbach's alpha .81 (Soliman et al., 2021). In the present study Cronbach's alphas were .88 and .81 , respectively. Disturbances for the two factors were permitted to covary in the path analysis model.

\subsubsection{Perceived Stress Scale}

This domain was measured by 10 items based on the perceived stress scale (Cohen, Kamarck, $\&$ Mermelstein, 1983). The scale was reworded to fit with Arab culture to address the overall pressures that a woman experienced within the past month. The items identify behavioral and personal reaction to life events that may cause a respondent to feel upset, irritated, loss of control, pressure, and incapable of handling personal problems. A prior study with Egyptian women found this scale had two factors: external stress, Cronbach's alpha .84, and confidence, Cronbach's alpha .88 (Soliman et al., 2021). In the present study Cronbach's alphas were .85 and .87 , respectively. Disturbances for the two factors were permitted to covary in the path analysis model. 


\subsection{Data Collection and Data Analysis}

A team of four college social work students were trained to distribute the study instrument. The data collection team provided subjects with general information about the intention of the survey to gather information from women on how they manage their daily lives and difficulties they may face in moving through streets and using transportation. Data were collected voluntarily by conveniently distributing the study instrument with consent forms to approximately 2000 subjects with no incentives. Subjects were approached to be part of the study and respond to the instrument during visits to governmental and administrative offices, while using public transportation, while participating in college classes, and during visits to open places, such as cafeterias. In general, participants were interested in the topic of the study. Most subjects responded to the instrument right away, but others decided to take it with them and mail it back to the team of data collectors. In any case, no names were attached to the instrument to protect privacy and assure confidentiality. Responses from 1,977 subjects were returned and included in the data analysis. Summary statistics describing the sample, found in Table 1, were computed using SPSS, version 25 (IBM, 2017), software.

Table 1. Means, standard deviations, and frequencies of sample demographics

\begin{tabular}{llll}
\hline Variable & Category & $M$ or $f$ & $S D$ or $\%$ \\
\hline Age in years & & 29.38 & 7.62 \\
Marital status & single & 462 & 23.4 \\
& engaged & 195 & 9.9 \\
married & 1039 & 52.6 \\
divorced & 167 & 8.4 \\
Education & widowed & 114 & 5.8 \\
& Illiterate & 57 & 2.9 \\
& Elementary & 38 & 1.9 \\
Secondary & 693 & 35.1 \\
Residence & Collage & 1102 & 55.7 \\
& Graduate & 87 & 4.4 \\
& Village & 924 & 46.7 \\
& Small town & 574 & 29.0 \\
& Large City & 479 & 24.2 \\
& Unemployed & 1295 & 65.5 \\
& Part time & 144 & 7.3 \\
& Full time & 538 & 27.2 \\
& & &
\end{tabular}


Type of work

$$
\text { clerk }
$$

544

27.5

.

salesperson

22

1.1

teacher

123

6.2

factory worker

8

.4

Type of dress

Hajab

1432

72.4

No Hijab

148

7.5

Niqab

195

9.9

Isdal no niqab

202

10.2

Leaving home

Every day

1596

80.7

Every week

312

15.8

Every month

69

3.5

Summary statistics describing the sample were computed using SPSS, version 25 (IBM, 2017), software.

All remaining analyses were conducted in R, version 3.5.1 (R Core Team, 2018). Descriptive statistics and Cronbach's alphas on the scale scores were computed using the psych package (Revelle, 2018). Data were screened for multivariate outliers using the mvoutlier package (Filzmoser \& Gschwandtner, 2018). Path analysis models were fit using the lavaan package (Rosseel, 2012) with maximum likelihood estimation.

\section{Results}

Scale scores were screened for outliers using Mahalanobis distance, and 266 cases $(13.5 \%)$ were identified as multivariate outliers and investigated. Nothing notable was found in the identified cases, and all cases were retained. Correlations and univariate statistics for the nine subscales are shown in Table 2. There were no missing data. All the variables had skew values that were within \pm 2 . The subscale scores for religion, awareness, media, and threat had kurtosis values exceeding \pm 2 . This accounted for $13.5 \%$ of the cases being identified as outliers despite no issues with those cases. However, none of the variables had kurtosis values exceeding \pm 7 . Thus, it was acceptable to analyze the data without further transformation.

Table 2. Correlations and univariate statistics for subscale scores

\begin{tabular}{|c|c|c|c|c|c|c|c|c|c|}
\hline & 1. & & & & & & & & \\
\hline Scale & Activity & 2. & 3. & 4. & 5. & 6. & 7. & 8. & 9. \\
\hline 2. Religiosity & 0.34 & & & & & & & & \\
\hline 3. Awareness & 0.10 & 0.42 & & & & & & & \\
\hline
\end{tabular}




\begin{tabular}{llllllllll} 
4. Media & 0.04 & 0.30 & 0.51 & & & & & & \\
5. Exposure & 0.14 & 0.07 & 0.04 & 0.14 & & & & & \\
6. Threat & 0.11 & 0.27 & 0.26 & 0.28 & 0.34 & & & & \\
7. Vulnerability & 0.17 & 0.20 & 0.11 & 0.19 & 0.47 & 0.51 & & & \\
8. External & 0.05 & 0.16 & 0.22 & 0.26 & 0.23 & 0.25 & 0.35 & & \\
9. Confidence & 0.08 & 0.13 & 0.22 & 0.17 & -0.02 & 0.16 & 0.09 & 0.32 & \\
\hline No. items & 6 & 9 & 12 & 8 & 10 & 5 & 7 & 5 & 5 \\
Alpha & 0.83 & 0.89 & 0.91 & 0.92 & 0.95 & 0.88 & 0.81 & 0.85 & 0.87 \\
Mean & 18.62 & 36.30 & 49.62 & 31.37 & 27.71 & 22.75 & 23.51 & 17.78 & 17.67 \\
Sd & 4.64 & 4.57 & 5.51 & 4.69 & 10.03 & 4.60 & 5.58 & 3.95 & 3.81 \\
Skew & -0.08 & -0.96 & -1.19 & -1.76 & 0.02 & -1.21 & -0.29 & -0.72 & -0.77 \\
kurtosis & -0.33 & 3.52 & 4.39 & 4.78 & -1.06 & 2.37 & -0.50 & 0.48 & 0.51 \\
\hline
\end{tabular}

Correlations and univariate statistics for the nine subscales are shown.

\subsection{Path Analysis}

The fit of the original path model needed some improvement, $\chi^{2}(6)=261.85, p<.001$, RMSEA $=.147,90 \%$ CI[.132,.162], SRMR $=.049$, CFI $=.913$. Examination of the correlation residuals found two values $(4.4 \%)$ with magnitudes greater than .10 . Theoretically appropriate model modifications were undertaken to improve these areas of the model. It should be noted that employing these model modifications dictated that the remaining analyses were of an exploratory nature.

A direct effect from Religiosity to Awareness was added to the model to account for how religiosity affects awareness of destabilizing social, political, and economic conditions. The addition of this path made theoretical sense because a strong sense of morality and how values should shape and govern behavior may heighten perception of societal conditions that counter such values. With this parameter included, the model had the following global fit values: $\chi^{*}(5)=54.59, p<.001, \mathrm{RMSEA}=.071,90 \% \mathrm{CI}[.055, .088], \mathrm{SRMR}=.028, \mathrm{CFI}$ $=.983$, and the fit of the model was significantly improved, $\chi^{2}(1)=207.26, p<.001$. Examination of the correlation residuals found one value $(2.2 \%)$ with magnitude greater than .10 .

A direct effect from Activity to Exposure was added to the model to account for how activity and social engagement affects exposure to sexual harassment. Given that the type of sexual harassment of focus in this study was primarily public harassment, it made sense that those who engage in more public activities (e.g., attending museums, playing sports, etc.) have 
more opportunities to be exposed to public harassment. With this parameter added to the model, the fit of the model improved significantly, $x^{2}(1)-37.89, p<.001$. Examination of the correlation residuals found no values with magnitude greater than .10. This final model, shown in Figure 2, had the following global fit values, $x^{2}(4)-16.70, p=.002$, RMSEA $=.040,90 \% \mathrm{CI}[.021, .061], \mathrm{SRMR}=.014, \mathrm{CFI}=.996$. The fit of this model appeared to be satisfactory. However, due to the likelihood of the model modifications having capitalized on chance relations in the sample, the model fit cannot truly be assessed without cross-validation using a new sample. Parameter estimates for the final model are shown in Table 3.

Table 3. Parameter estimates for the final model

\begin{tabular}{|c|c|c|c|c|}
\hline Parameter & $\begin{array}{l}\text { Unstandardized } \\
\text { estimate }\end{array}$ & Standard Error & $p$ & $\begin{array}{l}\text { Standardized } \\
\text { estimate }\end{array}$ \\
\hline Activity $\rightarrow$ Threat & -0.010 & 0.021 & 0.626 & -0.010 \\
\hline Religiosity $\rightarrow$ Threat & 0.160 & 0.023 & $<.001$ & 0.159 \\
\hline Awareness $\rightarrow$ Threat & 0.075 & 0.021 & $<.001$ & 0.090 \\
\hline Media $\rightarrow$ Threat & 0.107 & 0.023 & $<.001$ & 0.110 \\
\hline Exposure $\rightarrow$ Threat & 0.135 & 0.010 & $<.001$ & 0.296 \\
\hline External $\rightarrow$ Threat & 0.101 & 0.026 & $<.001$ & 0.087 \\
\hline Confidence $\rightarrow$ Threat & 0.092 & 0.026 & $<.001$ & 0.076 \\
\hline Activity $\rightarrow$ Vulnerability & 0.088 & 0.024 & $<.001$ & 0.073 \\
\hline Religiosity $\rightarrow$ Vulnerability & 0.132 & 0.027 & $<.001$ & 0.108 \\
\hline Awareness $\rightarrow$ Vulnerability & -0.033 & 0.024 & 0.159 & -0.033 \\
\hline Media $\rightarrow$ Vulnerability & 0.062 & 0.027 & 0.022 & 0.052 \\
\hline Exposure $\rightarrow$ Vulnerability & 0.215 & 0.011 & $<.001$ & 0.387 \\
\hline External $\rightarrow$ Vulnerability & 0.338 & 0.029 & $<.001$ & 0.240 \\
\hline Confidence $\rightarrow$ Vulnerability & -0.006 & 0.03 & 0.849 & -0.004 \\
\hline Activity $\rightarrow$ Exposure & 0.288 & 0.047 & $<.001$ & 0.133 \\
\hline Awareness $\rightarrow$ Exposure & -0.115 & 0.046 & 0.013 & -0.063 \\
\hline Media $\rightarrow$ Exposure & 0.273 & 0.054 & $<.001$ & 0.128 \\
\hline External $\rightarrow$ Exposure & 0.614 & 0.059 & $<.001$ & 0.242 \\
\hline Confidence $\rightarrow$ Exposure & -0.299 & 0.06 & $<.001$ & -0.114 \\
\hline Religiosity $\rightarrow$ Awareness & 0.339 & 0.023 & $<.001$ & 0.282 \\
\hline Media $\rightarrow$ Awareness & 0.469 & 0.023 & $<.001$ & 0.400 \\
\hline
\end{tabular}




$\begin{array}{lllll}\text { External } \rightarrow \text { Awareness } & 0.054 & 0.027 & 0.045 & 0.039 \\ \text { Confidence } \rightarrow \text { Awareness } & 0.152 & 0.028 & <.001 & 0.105 \\ \text { Activity } \rightarrow \text { External } & 0.036 & 0.019 & 0.051 & 0.042 \\ \text { Media } \rightarrow \text { External } & 0.213 & 0.018 & <.001 & 0.253 \\ \text { Activity } \rightarrow \text { Confidence } & 0.057 & 0.018 & 0.002 & 0.069 \\ \text { Media } \rightarrow \text { Confidence } & 0.137 & 0.018 & <.001 & 0.169 \\ \text { Disturbance(External) } \leftrightarrow & & & & \\ \text { Disturbance(Confidence) } & 4.119 & 0.335 & <.001 & 0.288 \\ \text { Disturbance(Threat) } \leftrightarrow & & & & \\ \text { Disturbance(Vulnerability) } & 7.072 & 0.451 & <.001 & 0.377 \\ \text { Residual variance(Threat) } & 16.309 & 0.519 & <.001 & 0.773 \\ \text { Residual variance(Vulnerability) } & 21.601 & 0.687 & <.001 & 0.697 \\ \text { Residual variance(Exposure) } & 91.251 & 2.902 & <.001 & 0.908 \\ \text { Residual variance(Awareness) } & 19.566 & 0.622 & <.001 & 0.648 \\ \text { Residual variance(External) } & 14.572 & 0.463 & <.001 & 0.933 \\ \text { Residual variance(Confidence) } & 14.034 & 0.446 & <.001 & 0.966\end{array}$

Parameter estimates for the final model, which had the following global fit values, $\chi^{2}(4)=16.70, p=.002, \mathrm{RMSEA}=.040,90 \% \mathrm{CI}[.021, .061], \mathrm{SRMR}=.014, \mathrm{CFI}=.996$.

Owing to the large sample size and corresponding high power in this study, the reporting of results is focused primarily on direct effects statistically significant at the .01 level. Religiosity, Awareness, Media, Exposure, External stress, and Confidence each had positive association with Threat. That is, as these factors increased, the sense of threat from sexual harassment also tended to increase. Of these factors, the most important was Exposure; Exposure had the largest standardized estimate of the direct effect on Threat (0.296).

Activity, Religiosity, Exposure, and External stress had positive association with Vulnerability. Again, as these factors increased, the sense of vulnerability to sexual harassment tended to increase. Of these factors, again, the most important was Exposure; Exposure had the largest standardized estimate of the direct effect on Vulnerability (0.387). Also notable was the standardized estimate of the direct effect of External stress on Vulnerability (0.240).

Exposure played an important role in the model as a partially intervening variable in the associations between predictors, such as Activity, Media, External stress, and Confidence, and outcomes, such as Threat and Vulnerability. Activity, Media, and External stress had a positive association with Exposure. As these factors increased, Exposure tended to increase. Confidence had a negative association with Exposure. As Confidence increased, Exposure tended to decrease. Of these factors, the most important was External stress; External stress 


\section{Macrothink}

had the largest standardized estimate of the direct effect on Exposure (0.242).

Awareness also was an important partially intervening variable in the associations between predictors, such as Religiosity, Media, and Confidence, and the outcome of Threat. Religiosity, Media, and Confidence had positive association with Awareness. As these factors increased, Awareness tended to increase. Of these factors the most important was Media; Media had the largest standardized estimate of the direct effect on Awareness (0.400). Also notable was the standardized estimate of the direct effect of Religiosity on Awareness (0.282). Media had a statistically significant direct effect on External stress. As Media increased, External stress also tended to increase. The size of the standardized estimate of this effect was also notable (0.253). Activity and Media had positive association with Confidence. As these factors increased, Confidence tended to increase.

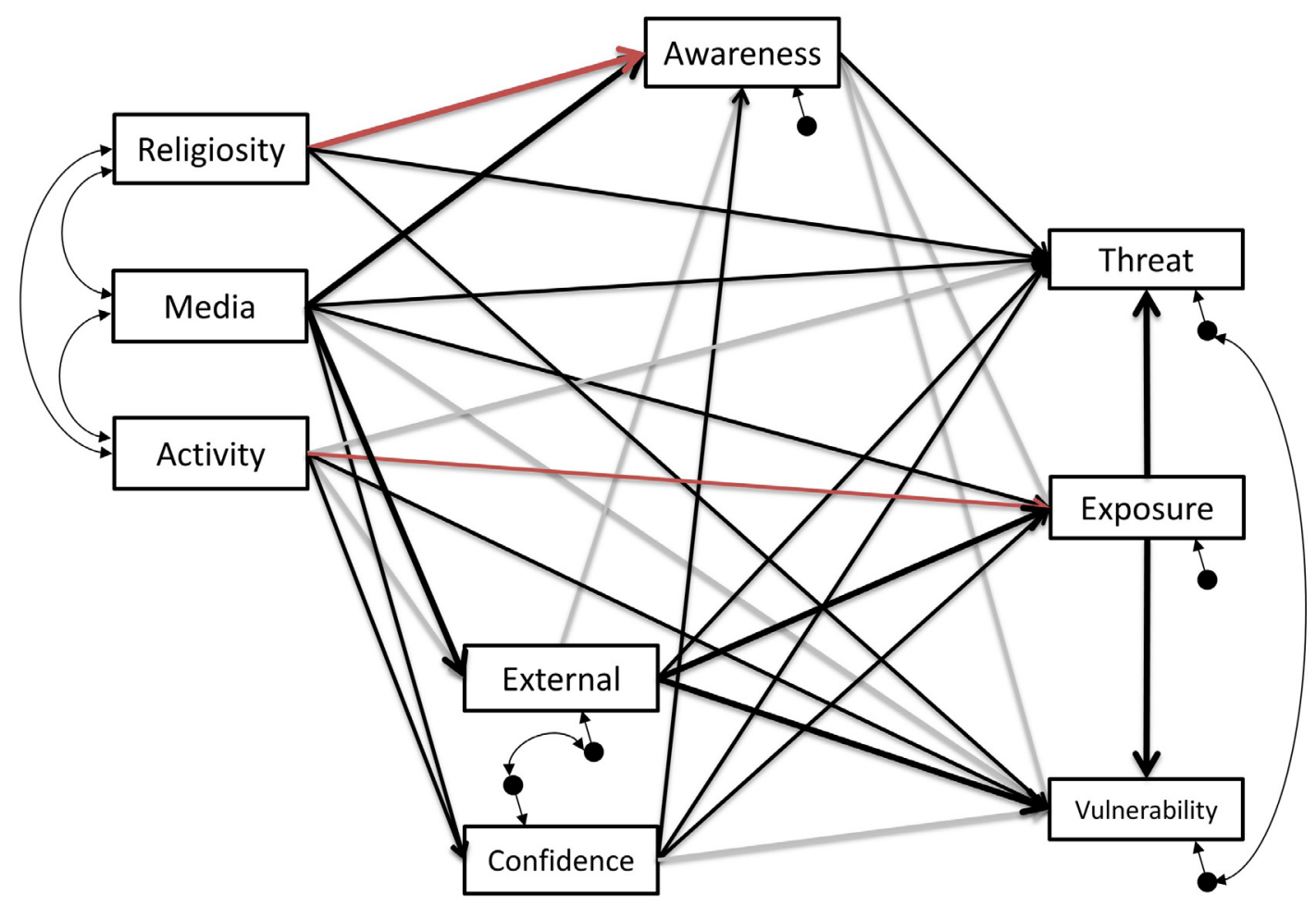

Figure 2. Final Model - Sexual Harassment Egypt

Final model with theoretically supported paths added (shown in red). Paths shown with grey arrows were statistically nonsignificant.

\section{Discussion}

This study investigated a complex web of beliefs and attitudes related to Egyptian women's perceptions of the threat of sexual harassment. The type of sexual harassment investigated was primarily public harassment (on the street). Variables related to public sexual harassment included the women's levels of activity and social engagement, religiosity, awareness of destabilizing social, political, and economic conditions, negative media influence, external stress, confidence in ability to cope with stress, exposure to sexual harassment, perception of 
threat of sexual harassment, and sense of vulnerability to street sexual harassment.

In this study, exposure to sexual harassment was found to be the strongest predictor of both perception of the threat of sexual harassment and a sense of vulnerability to sexual harassment. External stress was also found to be a substantial predictor of vulnerability. However, because of the cross-sectional nature of the data, it is possible that this effect is the reverse of how it was modeled in this study. That is, a heightened sense of vulnerability to street harassment may lead to a heightened sense of external stress. Likewise, external stress was found to be an important predictor of exposure to sexual harassment, but it is possible that exposure to street sexual harassment leads to a heightened sense of external stress.

The Egyptian women's awareness of societal social, political, and economic conditions was also found to be a significant predictor of their perception of the threat of street sexual harassment, even after controlling for the direct effects of activity and social engagement, religiosity, negative media influence, external stress, confidence in ability to cope with stress, and exposure to sexual harassment. In this study both religiosity and perceptions of negative media influence were found to be substantial predictors of Egyptian women's awareness of the social, political, and economic conditions that may contribute to the practice of sexual harassment in society. The women's perceptions of negative media influence was also found to have a substantial effect on external stress.

\subsection{Limitations and Implications for Future Research}

Two paths were not anticipated based on the literature but were added to the model in this study to remediate areas in the model that were a poor fit to the data. These effects were found to be useful in this study but require further research. An effect of religiosity on awareness of the social, political, and economic conditions was added to the model. It is plausible that a strong sense of morality and how values should shape and govern behavior may heighten perception of societal conditions that counter such values.

An effect of the women's levels of activity and social engagement on exposure to sexual harassment was also added to the model. Given that the type of sexual harassment of focus in this study was primarily public harassment (on the street), it made sense that those who engage in more public activities (e.g., attending museums, playing sports, etc.) have more opportunities to be exposed to public harassment. It should be made clear that the presence of this latter effect is different from victim blaming. As with any violence perpetrated by a stranger or acquaintance, becoming a victim of such violence is more likely when we are in locations that increase interactions with strangers and acquaintances. That fact does not suggest that engaging in public activities invites violence or that a person engaging in public activities deserves to be victimized.

Despite theoretical justification, the model modifications employed in this study may have capitalized on chance relations in the sample. Cross-validation with a new sample is warranted to assess whether the introduced parameters have enduring value. It is important to remember that the path model investigated in this study is only one possible representation of the relations among the variables. Alternative models may explain the data just as well or 
better than the model fitted in this study.

\subsection{Implications for Social Work Education}

This study has provided specific findings that can be used as a basis for improving coverage of the topic of sexual harassment in the social work curriculum. For example, greater levels of awareness of destabilizing social, political, and economic conditions were associated with lower levels of exposure to sexual harassment, even after controlling for the level of activity and social engagement of the women in the study. Thus, the topic of awareness of destabilizing social, political, and economic conditions can be used to develop models that enhance prevention. On the other hand, women's increased perception of negative media influence was associated with increased exposure. Thus, curricula focused on helping social workers increase women's perception of negative media influence is unlikely to have a direct benefit, at least not through the women themselves. The effect may be different for men, a demographic excluded from this study. On the micro level of human behavior and social environment knowledge, models of intervention with victims of sexual harassment can also benefit in addressing traumatic stress and other mental health symptoms.

On the macro practice level, it is critical to realize how society can become aware of such negative phenomenon and what models of practice are important to work with community groups and different constituencies to learn the magnitude of the phenomenon and its various impacts on victims and society. Policy classes can be enhanced by discussing the importance of developing policies that address the impact of the media on the dehumanization of women and emphasize the need to decrease violence and protect women. Finally, in research class, participatory research can be included to encourage community members to present their views on the appropriate ways of understanding the causes of sexual harassment within a cultural context and identify the direct and indirect factors related to such a phenomenon (Soliman, et al., 2020).

\section{References}

Abu-Alkhair, M. S. (2015). Body image disorder as a modified variable in the relationship between the trend towards sexual harassment and self-esteem among university students. College of Liberal Arts Journal, 74, 139-216.

Abu-Raiya, H. (2008). A psychological measure of Islamic religiousness: Evidence for relevance, reliability, and validity. (Doctoral dissertation). Graduate College of Bowling Green. https://doi.org/10.1037/t04021-000

State University.

Al-Bakar, A. M., Al-Adailah, L. M., \& Al-Nasblisi, H. H. (2017). Sexual harassment at universities: Causes and consequences. Dirasat Human \& Social Sciences, 44(1), 27-42. https://doi.org/10.12816/0040543

Al-Issa, I. (2000). Religion and psychopathology. In Al-Issa (Ed.), Al-Junun: Mental illness in the Islamic world (pp. 3-42). Madison, CT: International Universities Press. 
Al-Kylani, R. M. (2014). Sexual harassment of women and the disruption of the value system in the Egyptian society. Arab Journal of Sociological Science, 1, 13-33.

Al-Motalka, F. I. (2017). Sexual harassment against Jordanian women and its relation with some variables: The view of Jordon University students. Studies in Humanity and Social Sciences Journal, 44(2), 16-34.

Al-Taiar, F. A. (2015). Sexual harassment in UAE middle schools: A student counselor' perspective. Police Thoughts Journal, Al-Sharja Police Academy, 24(40), 6-21.

Alcoff, L. M. (2009). Discourses of sexual violence in a global framework. Philosophical Topics, 37(2), 123-139. https://doi.org/10.5840/philtopics20093728

Amin, G. (2006). Socio-economic interpretations of the west el Balad events. Presented at the IGWS sexual harassment Forum, December 4, 2006, Cairo.

Atkinson, B. E., \& Malony, H. N. (1984). Religious maturity and psychological distress among older Christian women. International Journal for the Psychology of Religion, 4, 165-179. https://doi.org/10.1207/s15327582ijpr0403_5

Aviana, C., \& O’Donhue, W. (2002). Sexual harassment and PTSD: Is sexual harassment diagnosable trauma? Journal of Traumatic Stress, 15(1), 69-75. https://doi.org/10.1023/ A:1014387429057

Baker, C. N. (2005). Images of women's sexuality in advertisements: A content analysis of black- and white-oriented women's and men's magazines. Sex Roles, 52, 13-27. https://doi.org/10.1007/s11199-005-1190-y

Baxi, P. (2001). Sexual harassment. Seminar. Retrieved from hhtp:/www.india=seminar.com/2001/505/505\%20pratisksha\%20baxi.htm

Blazer, D., \& Palmore, E. (1976). Religion and aging in a longitudinal panel. The Gerontologist, 16, 82-85. https://doi.org/10.1093/geront/16.1_Part_1.82

Bo-Shaljeem, H. (2017). A sociological analysis of the reality of sexual harassment against children in Algerian society. Generations of Social and Humanitarian Sciences, 30, 322-348.

Carco, M., \& Fayolle, A. (2017). Enhancing and empowering women for comprehensive and sustainable industrial development in the Middle-east and North Africa. Report prepared for the United Nations Industrial Development Organization (UNIDO). Vienna, Austria.

Cikara, M., \& Eberhard, J. L., \& Fiske, S. T. (2011). From agent to object: Sexist attitudes and neural responses to sexualized target. Journal of Cognitive Neuroscience, 23, 540-551. https://doi.org/10.1162/jocn.2010.21497

Cohen, S., Kamarck, T., \& Mermelstein, R. (1983). A global measure of perceived stress. Journal of Health and Social Behavior, 24(4), 385-396. https://doi.org/10.2307/2136404

Conely, T. D., \& Ramsey, L. R. (2011). Killing us softly? Investigating portrayals of men and women in contemporary magazine advertisements. Psychology of Women Quarterly, 35, 
469-478. https://doi.org/10.1177/0361684311413383

Cowan, G., \& Ullman, J. B. (2006). In-group rejection among women: The role of personal inadequacy. Psychology of Women Quarterly, 30, 299-409. https://doi.org/10.1111/j. 1471-6402.2006.00315.x

Crittenden, C. A. (2009). Examining attitudes and perceptions of sexual harassment on a university campus: What role do myths and stereotype play? (Master's thesis.) The University of Tennessee, TN, Chattanooga.

Dhilon, M., \& Bakaya, S. (2014). Street harassment: A qualitative study of the experiences of young women in Delhi. Sage Open, (July-September), 1-11. https://doi.org/10.1177/215824 4014543786

Egyptian Center for Women's Rights. (2017). Campaign against sexual harassment. Retrieved from http//:www.ahewar.org/eng/show.art.asp?aid=292

El-Ashmawy, N. (2017). Sexual harassment in Egypt: Class struggle, state oppression and women's empowerment. Hawwa, 15(3), 225-256. https://doi.org/10.1163/15692086 $-1234-1238$

Estrada, A. X., Olson, K. J., Harbke, C. R., \& Berggren. A. W. (2011). Evaluating a brief scale measuring psychological climate for sexual harassment. Military Psychology, 23, 410-432. https://doi.org/10.1080/08995605.2011.589353

Fahd, A. A. (2015). Sexual harassment in middle schools: Students' perceptions in UAE. Al-Sharja Police Academy Journal, 24(94), 24-35.

Filzmoser, P., \& Gschwandtner, M. (2018). mvvoutlier: Multivariate outlier detection based on robust methods. $\mathrm{R}$ package version 2.0.9. Retrieved from https://CRAN.R-project.org/package=mvoutlier

Fineran, S., \& Bennett, L. (1998). Teenage peer sexual harassment: Implications for practice and education. Social Work, 43(1), 55-64. https://doi.org/10.1093/sw/43.1.55

Fitzgerald, L. F., Magley, V. J., Drasgow, F., \& Waldo, C. R. (1999). Measuring sexual harassment in the military. The sexual harassment questionnaire (SEQ-DoD). Military Psychology, 11(3), 234-63. https://doi.org/10.1207/s15327876mp1103_3

Gad-Allah, A. A. (2016). A suggested program from a generalist social work perspective to educate middle school students about the impact of sexual harassment - Egypt. Egyptian Social Workers Association Journal, 55, 33-48.

Ghanem, M. H. (2015). Sexual harassment for males and females: A field study in the Egyptian Arab reality. Egypt: Al-Anglo Publisher.

Bent-Goodley, T. B. (2018). Necessity of trauma-informed practice in contemporary social work. National Association of Social Workers, 64(1), 5-7. https://doi.org/10.1093/sw/swy056

Gutek, B., A., \& Koss, M. P. (1993). Changed women and changed organizations: 
Consequences of and coping with sexual harassment. Journal of Vocational Behavior, 42(1), 28-48. https://doi.org/10.1006/jvbe.1993.1003

Hassan, R. M. (2008). Sexual harassment from verbal harassment to rape. Cairo, Egypt: The Central Institute for Sociological Studies, Egyptian Center for Women's Rights.

Heflick, N. A., \& Goldenberg, G. L. (2014). Seeing eye to body: The literal objectification of women. Psychological Science, 23(3), 225-229. https://doi.org/10.1177/0963721414531599

Ilahi, O. O. (2009). Gendered contestations: An analysis of street harassment in Cairo and its implications for women's access to public spaces. Retrieved from http://www.auc-egypt.edu/gapp/igws/graduate/documents/surfacing-vol2n_05ilahi.pdf

Jensen, I. W., \& Gutek, B. A. (1982). Attributions and assignment of responsibility in sexual harassment. Journal of Social Issues, 38(4), 121-136. https://doi.org/10.1111/j.15404560.1982.tb01914.x

Koenig, H. G., Kavel, J. N., \& Ferrel, C. (1988). Religion and well-being in later life. The Gerontologist, 28, 18-28.

Koenig, H. G., \& Larson, D. B. (2001). Religion and mental health: Evidence of association. International Review of Psychiatry, 13, 67-78.

Krause, N., \& Tran, T.V. (1989). Stress and religious involvement among elder blacks. Journal of Gerontology: Social Sciences, 44, S4-S13. https://doi.org/10.1093/geronj/44.1.S4

Laniya, O. O. (2005). Street smut: Gender, media and legal power dynamics of street harassment, or hey sexy and other verbal ejaculations. Colombia Journal of Gender \& Law, $14,91-142$.

Laurio, A. (2020). Social workers tackle issue of sexual assault. NASW News, 62(10), 1-10.

Lichty, L. F., Campbell, R. (2012). Targets and witnesses: Middle school students' sexual harassment experiences. Journal of Early Adolescence, 32(3), 414-430. https://doi.org/10.1177/0272431610396090

Linder, K. (2004). Images of women in general interest and fashion magazine advertisements from 1955-2002. Sex Roles, 51, 409-421. https://doi.org/10.1023/B.SERS.0000049230. $86869.4 \mathrm{~d}$

Mackenize, C., Rogers, W., \& Dodds, S. (Eds). (2014). Vulnerability: New essay in ethics and feminist philosophy. New York, NY: Oxford Press. https://doi.org/10.1093/acprof:oso/ 9780199316649.001.0001

Moylan, C. A., \& Wood, L. (2016). Sexual harassment in social work field placement: Prevalence and characteristics. Journal of Women \& Social Work, 31(4), 405-417. https://doi.org/10.1177/0886109916644643

Nardulli, P. F., Kalev, H., Leetaru, K. H., \& Hayes, M. (2011). Gauging civil unrest with speed data: The societal stability and the instability of civil unrest. IL: Cline Center for 
Democracy University of Illinois at Urbana-Champaign.

O’Keefe, N. K., Brockopp, K., \& Chew, E. (1986). Teen dating violence. Social Work, 31, 465-468. https://doi.org/10.1093/sw/31.6.465

Okeal, A. (2015). Reluctance to marry and sexual assault against children: A field study. Algulfa University Research Studies, 20, 139-216.

Ormerod, A. J., Collinsworth, L. L., \& Perry, L. A. (2008). Critical climate: Relations among sexual harassment, climate, outcomes for high school girls and boys. Psychology of Women Quarterly, 32, 113-125. https://doi.org/10.1111/j.1471-6402.2008.00417.x

Phadke, S. (2013). Unfriendly bodies, hostile cities: Reflections on loitering and gendered public space. Economic and Political Weekly, 48(39), 50-59.

R. Core Team. (2018). R: A language and environment for statistical computing. Vienna, Austria: R Foundation for Statistical Computing. Retrieved from https:/www.R-project.org/

Radwan, S., \& Referiz, J. L. (2006). Women and economic development in the Mediterranean region. Brussels, Belgium: Euro- Mediterranean Forum of Institutes of Economic Sciences, European Commission.

Revelle, W. (2018). psych: Procedures for personality and psychological research. R package version 1.8.12. Evanston, Illinois: Northwestern University. Retrieved from https://CRAN.R-project.org/package=psych

Rosseel, Y. (2012). lavaan: An R package for structural equation. Journal of Statistical Software, 48(2), 1-36. https://doi.org/10.18637/jss.v048.i02

Sarewitz, D., Pielke, R., \& Keykhah, M. (2003). Vulnerability and risk: Some thoughts from a political and policy perspective. Risk Analysis, 23(4), 805-811. https://doi.org/ $10.1111 / 1539-6924.00357$

Schwartz, R. McMahon, S., \& Broadnax, J. (2015). A review of sexual assault information on college websites. Health and Social Work, 40(4), 275-282. https://doi.org/10.1093/ hsw/hlv064

Soliman, H. H., Abdelmlnem, A, A., \& Koran, J. (2020). Adolescents' perception of the threat of sexual harassment: The development of an index. Journal of Child Sexual Abuse, 29(5), 570-585. https://doi.org/10.1080/10538712.2019.1667469

Soliman, H., Abdelmlnem, A, A., \& Koran, J. (2021). Measuring Egyptian women's vulnerability to sexual harassment threat: Reliability and validity evidence. Egyptian Journal of Social Work, 11(1), 17-34. https://doi.org/10.21608/ejsw.2020.44693.1110

Stanley, D. (2000). Student-on-student sexual harassment. New York, NY: The Rosen Publishing Group.

Swim, J. K., \& Hyers, L. L. (1999). Excuse me-What did you see? Women's public and private responses to sexist remarks. Journal of Experimental Social Psychology, 35, 68-88. 
https://doi.org/10.1006/jesp.1998.1370

Vera-Gray, F. (2016). Men's stranger intrusions: Rethinking street harassment. Women's Studies International Forum, 58, 9-17. https://doi.org/10.1016/j.wsfi.2016.04.001

United Nation Population Fund (UNPF). (2015). The Egypt Economic Cost of Gender-Based Violence survey. Cairo, Egypt: The Central Agency for Public Mobilization and Statistics (CAPMAS).

Wasti, S. A., Bergman, M. E., Glomb, T. M., \& Drasgow, T. (2000). Test of the cross-cultural generalizability of a model of sexual harassment. Journal of Applied Psychology, 85(5), 766-778. https://doi.org/10.1037/0021-9010.85.5.766

Willness, C., Steel, P., \& Lee, K. (2017). A meta-analysis of the antecedents and consequences of workplace sexual harassment. Personnel Psychology, 60, 127-162. https://doi.org/10.1111/j.1744-6570.2007.00067.x

Wilson, D. R. (2010). Health consequences of childhood sexual abuse. Prospect Psychiatric Care, 46(1), 56-64. https://doi.org/10.1111/j.1744-6163.2009.00238.x

\section{Copyright Disclaimer}

Copyright reserved by the author(s).

This article is an open-access article distributed under the terms and conditions of the Creative Commons Attribution license (http://creativecommons.org/licenses/by/4.0/). 